\title{
Is the Configuration of Indian Stock Market Weakly Efficient?
}

\author{
Aditya Prasad Sahoo \\ Ph.D. Research Scholar, KSOM, KIIT University, Bhubaneswar, Odisha, India \\ https://orcid.org/0000-0003-4399-2604
}

\section{OPEN ACCESS}

Manuscript ID:

COM-2021-09033982

Volume: 9

Issue: 3

Month: July

Year: 2021

E-ISSN: 2582-6190

Received: 30.03 .2021

Accepted: 14.05.2021

Published: 01.07.2021

Citation:

Sahoo, Aditya Prasad.

"Is the Configuration of Indian Stock Market Weakly Efficient?"

ComFin Research, vol. 9, no. 3, 2021, pp. 1-6.

DOI:

https://doi.org/10.34293/

commerce.v9i3.3982

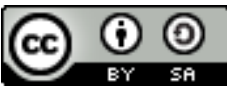

This work is licensed under a Creative Commons AttributionShareAlike 4.0 International License

\section{Abstract}

The main aim of this study is to find out the whether the Indian stock market efficiency is in weak form. The aim of this study is to look into the Indian Stock Market's lack of market performance. From 2000 to 2015, sample is gathered on a daily, weekly, and monthly basis. Unit Root Test, Run Test, and KS Test are used to examine the data. According to the findings, The Runs Test disproves the existence of a random walk and demonstrates that the Indian stock market is not weakly efficient. Through stock valuation strategies, technical and fundamental analysts may generate volatile returns.

Keywords: Run test, Efficiency, KS test, ADF test, Volatility, Random-walk

\section{Introduction}

Academic scholars continue to debate the idea of market efficiency. When we look at the evidence in scholarly literature that supports market efficiency, it appears how these ideas are both rational and reasonable. Even so, based on the recent performance of mutual funds and other investment firms, one may be cynical of certain legitimacy in many global financial markets. Mutual funds have made considerable progress over the last several years, as evidenced by their increased number and growth. The notion of Fama and French (1970) regarding Market Efficiency was already recognized by researchers but nevertheless academician raises questions on the idea of treating each investor similarly. The assertions that critiques provided resisting the hypothesis is that how a capable and skilled investor can act the same way in which a normal and ineptitude investor does. Stock prices, according to Fama and French (1970), are not predictable. They base their argument on certain premises, such as that informational accessibility is free, that a large number of investors react quickly to information, and that a lot of investors participate in stock markets. Their research is significant because it is based on the premise that if all information is comparable and no one can achieve any advantage in terms of information, it is inconceivable for him to obtain abnormal market benefits. If everyone in the market recognizes what everyone else knows, it seems that buyers and sellers are gazing simultaneously the same picture through diverse viewpoints. In such a case, why would a seller be willing to share his profit with others? It appears to be true that if both parties have equal access to information, neither will be willing to put their money in another's pocket. Prices will move so rapidly in light of new information in such a market nobody will be able to locate a lag time to purchase any undervalued stock. Prices, per the principle of market efficiency, previously represent all current information. Put simply, in an efficient market, any abnormal returns received by individual investors are profitable bets that may or may not be due to their good fortune. Is it feasible, either as everyone has the identical information as the others? Is it realistic to assume everyone in the business to behave in the same way? 
Is it really possible to treat each investor with respect and have them always react appropriately? "These seem to be the concerns for the majority of opponents of the market efficiency theory. Even if we assume that all investors have the same knowledge, there is no guarantee that they will use it in the same way. According to studies, portfolio allocation is guided by liquidity needs, time spans, and risk tolerance; else, each investor will behave similarly" (Blanc and Rachlinski 2005). "It would be unrealistic to predict any investor to act rationally all of the time. Moreover, in certain cases where information becomes a common perception, it can appear true. However, our point here is that it would be a case only when many of the irrational investors are kicked out of the market and remaining are the rational ones or the one who become rational after losing parts of their wealth" Moustafa, M.A. (2004). If we assume the investors value securities employing specified equations and methodology, we may assume that investors will respond similarly when given the same details and subjected to certain types of tests. Their responses to such details, nevertheless, are influenced by the timing of their decisions, which are cantered on their risk tolerance and liquidity requirements. However, the issue is how an investor will learn what the other investors will do with the identical details, whether they will do so, and how long it will take for a security to be fairly priced. After all, in lieu of conflicting feelings, resolving the debate in favour of one view point would be challenging. In the following section of this research, a few studies that have tested this principle are listed, with mixed results.

\section{Literature Review}

Srinivasan (2010) investigated the relevance of weak form efficiency for two of India's main stock exchanges: The National Stock Exchange (NSE) and the Bombay Stock Exchange (BSE) (BSE). He employed data from 1997 to 2010 . He combined the random walk hypothesis test with unit root tests such as the Augmented Dickey-Fuller (1979) and PhillipsPeron (1988) tests. For the period 2000-2013, Phan \& Zhou (2014) examined the Vietnam emerging stock market. Using the autocorrelation test, variance ratio test, and runs tests, the Vietnamese stock market was found to be inefficient in the early stages of the analysis, but showed a steady improvement in the market's operations in the last years of the study period, with evidence supporting the random walk hypothesis in only the VN-index (one of the Vietnamese stock market's indices). (Hartika Arora, et al., 2017) Using interval return data for the top 10 commonly traded stocks and the Nifty 50 from January 1, 2009 to March 31, 2011, this paper attempts to check the poor form of the efficient market hypothesis. The author uses high frequency data to evaluate the poor type of performance, which is needed to monitor the stock market's intraday certainty characteristics. The Augmented Dickey-Fuller (ADF) test was used to validate the data's normality, the ARMA experiment was used to confirm autocorrelations, and the GARCH $(1,1)$ model was used to symbolise volatility. (Ajju Patel, et al. 2018) This research studies some of the most critical market irregularities in the stock exchange indexes in France, Germany, Italy and Spain between 2001 and 2010. Statistical methods such as the GARCH model and the OLS regression are used in this study to mathematically verify the distribution of results and their autocorrelation. This analysis has some market-specific results, rather than significant anomalies. (Vidya A, 2018) The study looked at the market efficiency notion in 10 securities through running tests and autocorrelation tests. The association among sample companies' prior stock prices and their prospective stock prices is observed to be quite poor. This proves that variations in prices are altered and that the market is weak.

\section{Objectives of the Study}

The main objective of the study is to find out whether the Indian stock market is weak form efficient or not.

\section{Research Methodology}

The study data comprise of Sensex's (Bombay Stock Exchange) daily, weekly and monthly closing values for the period of 2000 to 2015. The weak EMH component is largely based on Random Walk hypothesis. The tests are thus designed to determine whether consecutive price movements are autonomous. The weak-form efficiency of 
stock markets are tested in this study. Descriptive statistics, Run test and Kolmogrov Srinov (KS) Testing was done with Microsoft Excel, SPSS and EVIEWS. In daily, weekly, and monthly stock indexes of BSE SENSEX the sustained compounded rate of return is measured according to the formula given. Return $=\mathrm{Rt}_{\text {mid }}=\mathrm{Ln}\left(\mathrm{MID}_{\mathrm{t}} / \mathrm{MID}_{\mathrm{t}-1}\right)$

In the above formulae

$$
\begin{aligned}
& \mathrm{Rt}_{\text {mid }}=\text { Return of market index } \\
& \mathrm{L}_{\mathrm{n}}=\text { Natural Log } \\
& \mathrm{MID}_{\mathrm{t}}=\text { Market index at times } \mathrm{t} \\
& \mathrm{MID}_{\mathrm{t}-1}=\text { Market index at times } \mathrm{t}-1
\end{aligned}
$$

\section{Hypothesis}

- $\mathrm{H}_{0}$ : The Stock Prices are non-random in SENSEX on the basis of Daily, Weekly and Monthly.

- $\mathrm{H}_{1}$ : The Stock Prices are random in SENSEX on the basis of Daily, Weekly and Monthly.

\section{Data Analysis and Interpretation}

Table 1: Descriptive Statistics

\begin{tabular}{|l|c|c|c|}
\hline \multicolumn{4}{|c}{ Descriptive Statistics } \\
\hline & Daily & Weekly & Monthly \\
\hline Mean & 1.101132 & 1.100113 & 1.100022 \\
\hline Median & 1.10021 & 1.10051 & 1.100031 \\
\hline Maximum & 1.022511 & 1.025331 & 1.042214 \\
\hline Minimum & 0.862446 & 0.896122 & 0.89179 \\
\hline Std. Dev. & 0.002010 & 0.003001 & 0.008675 \\
\hline Skewness & -0.14779 & -1.0682 & -0.69972 \\
\hline Kurtosis & 5.630214 & 7.47636 & 8.246405 \\
\hline Jarque-Bera & 1586.142 & 715.3217 & 299.2801 \\
\hline Probability & 0 & 0 & 0 \\
\hline Sum & 2913.283 & 609.2884 & 142.291 \\
\hline Source: Auth & & & \\
\hline
\end{tabular}

Source: Author's Calculation

In table 1, the characteristics of chosen data sample are analysed using descriptive statistics. In this study Indian stock exchange index is taken on the basis of daily, weekly and monthly. Mean represents the average index return for the study period and the S.D. shows the uncertainty of those yields. In the case of daily, weekly and months data, Indian Stock market offers similar returns. Moreover, the variance from daily and weekly prices is greater in case of monthly data.
Table 2: Lag Structure of BSE SENSEX Returns Lag Structure

\begin{tabular}{|c|c|c|c|}
\hline \multicolumn{4}{|c|}{ Lag Structure } \\
\hline Lag & Monthly & Daily & Weekly \\
\hline 0 & 3.31113 & 3.152211 & 2.336100 \\
\hline 1 & -4.51422 & -2.98289 & $-3.0157^{*}$ \\
\hline 2 & $-4.5733^{*}$ & $-4.1706^{*}$ & -3.00103 \\
\hline 3 & -4.84319 & -4.16597 & -3.00925 \\
\hline 4 & -4.63142 & -3.87515 & -2.06954 \\
\hline 5 & -4.31122 & -2.03232 & \\
\hline 6 & -4.37988 & -2.00158 & \\
\hline 7 & -4.93100 & -1.9644 & \\
\hline 8 & -2.92751 & & \\
\hline 9 & -2.77119 & & \\
\hline 10 & -2.1479 & & \\
\hline 11 & -2.12521 & & \\
\hline 12 & -2.1902 & & \\
\hline
\end{tabular}

Source: Author's Calculation

A suitable lag formation should be mentioned for the data while using the unit root test. The root test unit is applied to lagged series values. The VAR methods is used to choose lag structure. Suitable lag length is regarded when $\mathrm{SC}$ is observed to be minimum (Shawarz Criteria). For daily data, 2 days Lag has been set at 2 weeks and monthly time series data display a least lag time of one month for weekly data lag formation according to SC value.

Table 3: Stationarity Test of BSE SENSEX Returns

\begin{tabular}{|c|c|c|c|c|}
\hline \multicolumn{5}{|c|}{ Unit Root Test } \\
\hline & $\begin{array}{c}\text { ADF } \\
\text { Level }\end{array}$ & $\begin{array}{c}\text { ADF 1st } \\
\text { Dif. }\end{array}$ & $\begin{array}{c}\text { PP } \\
\text { Level }\end{array}$ & $\begin{array}{c}\text { PP 1st } \\
\text { Dif. }\end{array}$ \\
\hline Daily & -1.460121 & $-29.47233^{*}$ & -1.5239 & $-39.00928^{*}$ \\
\hline Weekly & -1.514111 & $-20.16010^{*}$ & -1.78213 & $-31.27190^{*}$ \\
\hline Monthly & -1.810079 & $-9.627817 *$ & -1.59110 & $-19.50391^{*}$ \\
\hline \multicolumn{5}{|c|}{ Critical Values } \\
\hline $1 \%$ & -4.213300 & -4.300031 & -4.21015 & -4.391109 \\
\hline $5 \%$ & -3.195120 & -3.133200 & -3.64010 & -3.471229 \\
\hline $10 \%$ & -3.292700 & -3.843911 & -3.73900 & -3.413640 \\
\hline
\end{tabular}

Source: Author's Calculation

In Table 3, it is clear from the results of Unit Root Test is that all the data relating to daily, weekly and monthly are non-stationary in nature but after the first difference it will become stationary, this reflects 
that Indian stock market is free from random walk theory. This will help the technical analyst if they will study the past price movement thoroughly. So as the Indian stock market is reflecting no evidences of weak form market efficiency, retail investors can outstrip by vividly ensuing the technical analysis.

Table 4: RUN Test of BSE SENSEX Returns

(Mean)

\begin{tabular}{|l|c|c|c|}
\hline \multicolumn{4}{|c|}{ Run Test (Mean) } \\
\hline & Daily & Weekly & Monthly \\
\hline Test Value & 1.0002 & 1.0009 & 1.0002 \\
\hline Cases $<$ Test Value & 1456 & 304 & 145 \\
\hline Cases $>=$ Test Value & 1457 & 305 & 1457 \\
\hline Total Cases & 2913 & 609 & 2913 \\
\hline Number of Runs & 1421 & 317 & 1421 \\
\hline Z & -4.101 & -4.137 & -4.100 \\
\hline Asymp. Sig. (2-tailed) & 0 & 0 & 0 \\
\hline
\end{tabular}

Source: Author's Calculation

In Table 4, Run Test find out that BSE SENSEX returns are non-normal in all the three cases that is daily, weekly and monthly. The table discloses expected number of runs in relation to the actual runs. In all the three format it is clear that the returns of Indian stock market are abnormal.

Table 5: RUN Test of BSE SENSEX Returns (Median)

\begin{tabular}{|l|c|c|c|}
\hline \multicolumn{4}{|c|}{ Run Test (Median) } \\
\hline & Daily & Weekly & Monthly \\
\hline Test Value ${ }^{\mathrm{a}}$ & $2.00 \mathrm{E}+00$ & $2.00 \mathrm{E}+00$ & $2.00 \mathrm{E}+00$ \\
\hline Cases $<$ Test value & 1411 & 268 & 1411 \\
\hline $\begin{array}{l}\text { Cases }>=\text { Test } \\
\text { value }\end{array}$ & 1502 & 341 & 1502 \\
\hline Total Cases & 2913 & 609 & 2913 \\
\hline Number of Runs & 1411 & 255 & 1411 \\
\hline Z & -4.38 & -4.813 & -4.58 \\
\hline $\begin{array}{l}\text { Asymp. Sig. } \\
\text { (2-tailed) }\end{array}$ & 0 & 0 & 0 \\
\hline
\end{tabular}

Source: Author's Calculation

In Table 5 also Run Test find out that BSE SENSEX returns are not normal in case of daily, weekly or monthly. The table discloses expected number of runs in relation to the actual runs. It is clear that in all the format Indian stock market returns are non-random as per the findings.
Table 6: Kolmogrov Srinov (KS) Test

\begin{tabular}{|c|c|c|c|}
\hline \multicolumn{4}{|c|}{ Test of Normality K-S } \\
\hline & Statistic & DF & Sig. \\
\hline Daily & $8.20 \mathrm{E}-01$ & $3.30 \mathrm{E}+02$ & 0 \\
\hline Weekly & 0.102 & 718 & 0 \\
\hline Monthly & 0.22 & 210 & 0 \\
\hline
\end{tabular}

Source: Author's Calculation

In Table 6, Kolmogrov Srinov (KS) reflect whether the data set is fit for the actual distribution. As per the output it is seen that BSE SENSEX index which is used as proxy for Indian Stock Market Returns is significant and the value for daily, weekly and monthly are abnormally distributed and the configuration of Indian Stock Market is not weakly efficient.

\section{Conclusion}

This research looked into the Indian stock market to check whether it is weakly efficient or inefficient. In the past years, the Indian Stock Market index peaked in history. In such cases, investors overestimate their ability to gain further. This research was carried out by using information from phases when the market experienced a lot of ups and downs. The Runs Test disproves the existence of a random walk and demonstrates that the Indian stock market is not weakly efficient. As a result, the Random Walk Model is unable to predict the behavior of share prices. Statistical tests are used to analyse the market's competitiveness and behaviour, but none of them succeed in proving the Indian Stock Market's efficiency. Inefficiency in financial markets has the real effect of causing variations in anticipated stock returns. Stock prices don't always represent the true value of the stocks when the market is inefficient. As a consequence, businesses with a poorer intrinsic price of the shares could have a thought-provoking time in raising the money.

\section{References}

Adams, Michael Anthony. "Fiscal Policy and Stock Market Efficiency in the USA: An ARDL Bounds Testing Approach." Journal of Accounting, Business and Finance Research, vol. 9, no. 2, 2020, pp. 73-81. 
ComFin Research

Ali, Sajid, et al. "Stock Market Efficiency: A Comparative Analysis of Islamic and Conventional Stock Markets." Physica A: Statistical Mechanics and Its Applications, vol. 503, 2018, pp. 139-153.

Alves, Luiz G., et al. "Collective Dynamics of Stock Market Efficiency." Scientific Reports, vol. 10, 2020.

Anagnostidis, P., et al. "Has the 2008 Financial Crisis Affected Stock Market Efficiency? The Case of Eurozone." Physica A: Statistical Mechanics and its Applications, vol. 447, 2016, pp. 116-128.

Arora, Haritika, et al. "Testing Weak-Form Efficiency of Indian Stock Market using High Frequency Data." Pacific Business Review International, vol. 10, no. 7, 2017, pp. 7-21.

Asiri, Batool, and Hamad Alzeera. "Is the Saudi Stock Market Efficient? A Case of Weak-form Efficiency." Research Journal of Finance and Accounting, vol. 4, no. 6, 2013, pp. 35-48.

Dai, Zhifeng, et al. "Efficient Predictability of Stock Return Volatility: The Role of Stock Market Implied Volatility." North American Journal of Economics and Finance, vol. 52, 2020.

Dicle, Mehmet F., and John Levendis. "Greek Market Efficiency and its International Integration." Journal of International Financial Markets, Institutions and Money, vol. 21, no. 2, 2011, pp. 229-246.

Dragota, Victor, and Elena Valentina Tilica. "Market Efficiency of the Post-Communist East European Stock Markets." Central European Journal of Operations Research, vol. 22, 2014, pp. 307-337.

$\mathrm{Du}$, Wenti. "News and Market Efficiency in the Japanese Stock Market." Journal of Behavioral Finance, 2020.

Fazlollahi, Negar, et al. "Evolving Time-varying Market Efficiency of Energy Stock Market." Environmental Science and Pollution Research, vol. 27, 2020.

Franzoni, Francesco, and Jose M. Marin. "Pension Plan Funding and Stock Market Efficiency." The Journal of Finance, vol. 61, no. 2, 2006, pp. 921-956.
Gozbasi, Onur, et al. "Re-examining the Turkish Stock Market Efficiency: Evidence from Nonlinear Unit Root Tests." Economic Modelling, vol. 38, 2014, pp. 381-384.

Guidi, Francesco, et al. "Weak-form Market Efficiency and Calendar Anomalies for Eastern Europe Equity Markets." Journal of Emerging Market Finance, vol. 10, no. 3, 2011, pp. 337-389.

Hamid, Kashif, et al. "Testing the Weak Form of Efficient Market Hypothesis: Empirical Evidence from Asia-Pacific Markets." International Research Journal of Finance and Economics, no. 58, 2010, pp. 121-133.

Hung, Jui-Cheng. "Deregulation and Liberalization of the Chinese Stock Market and the Improvement of Market Efficiency." The Quarterly Review of Economics and Finance, vol. 49, no. 3, 2009, pp. 843-857.

Khan, A.Q., et al. "Testing Weak Form Market Efficiency of Indian Capital Market: A Case of National Stock Exchange (NSE) and Bombay Stock Exchange (BSE)." African Journal of Marketing Management, vol. 3, no. 6, 2011, pp. 115-127.

Khandoker, M.S., et al. "Tests of Weak-form Market Efficiency of Dhaka Stock Exchange: Evidence from Bank Sector of Bangladesh." Interdisciplinary Journal of Research in Business, vol. 1, no. 9, 2011, pp. 47-60.

Lalwani, Vaibhav, and V.V. Meshram. "Stock Market Efficiency in the Time of COVID-19: Evidence from Industry Stock Returns." International Journal of Accounting \& Finance Review, vol. 5, 2020, pp. 40-44.

Lamouchi, Rim Ammar. "Long Memory and Stock Market Efficiency: Case of Saudi Arabia." International Journal of Economics and Financial Issues, vol. 10, 2020, pp. 29-34.

Lim, Kian-Ping, et al. "Financial Crisis and Stock Market Efficiency: Empirical Evidence from Asian Countries." International Review of Financial Analysis, vol. 17, no. 3, 2008.

Mehmood, Mian Saqib, et al. "Stock Market Prices Follow the Random Walks: Evidence from the Efficiency of Karachi Stock Exchange." European Journal of Economics, Finance 
and Administrative Sciences, no. 51, 2012, pp. 71-80.

Mishra, P.K. "Weak Form Market Efficiency: Evidence from Emerging and Developed World." The Journal of Commerce, vol. 3, no. 2, 2011, pp. 26-34.

Moustafa, M.A. "Testing the Weak-Form Efficiency of the United Arab Emirates Stock Market." International Journal of Business, 2004.

Omar, Muhammad, et al. "Testing of Random Walks in Karachi Stock Exchange." Elixer Online Journal, vol. 54, 2013, pp. 12293-12299.

Patel, Nikunj, et al. "Testing weak form of Market Efficiency: A Study on Indian Stock Market." International Journal of Management \& Business Studies, vol. 8, no. 4, 2018, pp. 9-11.

Phan, Khoa Cuong, and Jian Zhou. "Market Efficiency in Emerging Stock Markets: A Case Study of the Vietnamese Stock Market." IOSR Journal of Business and Management, vol. 16, 2014, pp. 61-73.

Rizvi, Syed Arun R., et al. "An Analysis of Stock Market Efficiency: Developed vs Islamic Stock Markets using MF-DFA." Physica A: Statistical Mechanics and its Applications, vol. 407, 2014, pp. 86-99.

Rossi, Matteo, and Ardi Gunardi. "Efficient Market Hypothesis and Stock Market Anomalies: Empirical Evidence in Four European Countries." Journal of Applied Business Research, vol. 34, no. 1, 2013, pp. 183-192.

Sachin, K., and Kantesha Sanningammanavara. "The Efficiency Testing of Weak Form of the Indian Stock Market." International Journal of Engineering and Management Research, vol. 4, no. 4, 2014, pp. 44-53.

Srinivasan, P. "Testing Weak-form Efficiency of Indian Stock Markets." Asia Pacific Journal of Research in Business Management, vol. 1, no. 2,2010

Stoian, Andreea, and Filip Iorgulescu. "Fiscal Policy and Stock Market Efficiency: An ARDL Bounds Testing Approach." Economic Modelling, vol. 90, 2020, pp. 406-416.

Tuyon, Jasman, and Zamri Ahmad. "Behavioural Finance Perspectives on Malaysian Stock Market Efficiency." Borsa Istanbul Review, vol. 16, no. 1, 2016, pp. 43-61.

Vidya, A. "An Empirical Study on Weak form Efficiency of Indian Stock Market." International Journal of Management Studies, vol. 5, no. 2, 2018, pp. 94-98.

Wang, Yudong, et al. "Analysis of Market Efficiency for the Shanghai Stock Market over time." Physica A: Statistical Mechanics and its Applications, vol. 389, 2010, pp. 1635-1642.

$\mathrm{Xu}$, Qifa, et al. "Social Media, Interaction Information and Stock Market Efficiency: Evidence from the Shenzhen Stock Exchange Easy Interaction Platform in China." AsiaPacific Journal of Accounting \& Economics, 2020.

Zarei, Safoora, and Sadegh Jafari. "Market Efficiency and Long-range Dependence: Evidence from the Tehran Stock Market." Asian Journal of Economics, Finance and Management, vol. 2, no. 2, 2020, pp. 20-28.

\section{Author Details}

Aditya Prasad Sahoo, Ph.D. Research Scholar, KSOM, KIIT University, Bhubaneswar, Odisha, India

Email ID: adityasahoo007@gmail.com 